\title{
On the English Translation of Color Words in Tang Poetry
}

\author{
Huang Shanshan ${ }^{1}$, Wang Feng ${ }^{2 \#}$ \\ ${ }^{1,2}$ School of Foreign Studies, Yangtze University, Hubei, 434023 PRC China.
}

\#corresponding author.

Type of Work: Peer-Reviewed

DOl: http://dx.doi.org/10.21013/jems.v15.n4.p3

\section{How to cite this paper:}

Huang, S., Wang, F. (2019). On the English Translation of Color Words in Tang Poetry. IRA International Journal of Education and Multidisciplinary Studies (ISSN 2455-2526), 15(4), 122-128.doi: http://dx.doi.org/10.21013/jems.v15.n4.p3

(C) Institute of Research Advances.

This work is licensed under a Creative Commons Attribution-Non Commercial 4.0 International License subject to a proper citation to the publication source of the work.

Disclaimer: The scholarly papers as reviewed and published by the Institute of Research Advances (IRA) are the views and opinions of their respective authors and are not the views or opinions of the IRA. The IRA disclaims of any harm or loss caused due to the published content to any party.

Institute of Research Advances is an institutional publisher member of Publishers International Linking Association Inc. (PILA-CrossRef), USA. The institute is an institutional signatory to the Budapest Open Access Initiative. Hungary advocating the open-access of scientific and scholarly knowledge. The Institute is a registered content provider under Open Access Initiative Protocol for Metadata Harvesting (OAI-PMH).

The journal is indexed \& included in WorldCat Discovery Service (USA), CrossRef Metadata Search (USA), WorldCat (USA), OCLC (USA), Open J-Gate (India), EZB (Germany) Scilit (Switzerland), Airiti (China), Bielefeld Academic Search Engine (BASE) of Bielefeld University, Germany, PKP Index of Simon Fraser University, Canada.

1. Huang Shanshan is a postgraduate of QX181 in the School of Foreign Studies, Yangtze University.

2. Wang Feng (corresponding author) is an Associate Professor in the School of Foreign Studies, Yangtze University. His research interests include translation studies, intercultural communication, and interpreting studies. 
ABSTRACT

The color word “青” frequently appears in Tang poetry and is deeply loved by poets because of its ambiguity. However, the multiple meanings of “青” also bring difficulties to translation activities. What color does it mean? Thus, from the perspective of Relevance Theory, this study discusses the three basic meanings of the color word "青", taking as examples the misunderstood words that contain "青” in several classical poems by Li Bai. To achieve the accurate translation of the color word “青”, the key is to achieve the optimal relevance, and thus the greatest contextual effect can be obtained.

Keywords: misunderstanding of “青”; Tang poetry; Relevance Theory; optimal relevance

\section{INTRODUCTION}

Fuzziness is an important feature of poetry, and ambiguous color words are often used by poets to express their meanings. According to some scholars, the color word “青” has appeared 6467 times in Full Collection of Tang Poetry（全唐诗）（Ying Li \& Ye Qiusheng, 2007); “青” can respectively refer to three colors, namely blue, black and green, which vary with the context. Relevance Theory holds that in communicative behaviour, each discourse stimulus assumes optimal relevance so that the recipient can get the greatest contextual effect with the least effort (Sperber \& Wilson, 1986). As a communicative act, translation can also be explained by the theory. According to A Critical Anthology of Tang Poetry and their English Translations (唐诗英译集注、比录、鉴评与索引), many color words in Li Bai's famous poems containing "青" tend to be mistranslated into English. Under the framework of Relevance Theory, the translator should greatly ensure the optimal relevance for the target reader to realize the informative intention and communicative intention of the original author (Zhou Yingli\& Xu Huiyan, 2018). Based on this, this study starts with the Relevance Theory and analyzes the English translation of the words containing the color word "青” in Tang poetry.

\section{ANALYSIS OF TRANSLATIONS}

\subsection{Research Status of the Color Word “青” in Tang Poetry}

China has been a country of poetry since ancient times. As the pinnacle of poetic creation, Tang poetry has received widespread attention from researchers at home and abroad. This charm of Tang poetry is mainly because of the extensive use of vague language. However, it is precisely these flexible words that make the translation face many problems. As an important part of the fuzzy language, ambiguous color words have been discussed regarding their similarities and differences, and the cultural factors behind them (Chen Lili, 1996; Zhao Jing, 1999; Zhang Xiaojian, 2002; Liang Manli, 2004) ). There are also studies which focus on the translation methods of English and Chinese color words (Peng Qiurong, 2001; Li Taizhi, 2004; Ji Lanfen; 2009). We can almost find all the corresponding English terms of basic Chinese color words, but "青" is not exactly equivalent to "blue" in English. In the existing research, there is not much research on the color word "青" in Tang poetry: Ying Li and Ye Qiusheng (2007) explore the three meanings of “青”, namely "blue”, “black” and "green”. Liu Suping (2010) sums up the main translations of the color word “青” in Tang poetry. Few studies have focused on the English translation of the color word “青” from a theoretical level. In this regard, this study tries to analyze and correct the misunderstanding of those words that contain the color word “青” in the classic poems of Li Bai from the perspective of Relevance Theory, and meanwhile, explore the realization of the greatest contextual effect in translating.

\subsection{The Evolution of the Color Word “青” and its Connotation}

The color word “青” plays an important part in Chinese culture. Xu Shen once mentioned in the Shuo Wen Jie Zi (说文解字, compiled between 100 to $121 \mathrm{CE}$ ) that there were five colors including "青" during the pre-Qin period (Before $221 \mathrm{BCE}$ ). In 
fact, from the Shang Dynasty, "青” has been among the five basic colors widely used until modern times (Yao Xiaoping, 1988).

“青" has rich connotations and can refer to three colors that are blue, black, and green in different contexts. According to Xu Chaohua (1988), (1) “青” means green when it’s used to describe the color of natural objects such as moss and green hills. (2) “青" means blue when it's used to describe the color of the sky and dyed clothes such as blue clothes and blue sky. (3) "青” means black when it's used to describe the color of hair and eyes such as black hair and black eyes.

\subsection{Misunderstanding of the Words Containing the Color Word “青”}

The misunderstood words selected in this article are from the three poems of Li Bai, which are "Mount Skyland Ascended in a Dream-A Song of Farewell”(梦游天姥吟留别), “Qiang Jin Jiu” (Please Drink the Wine, 将进 酒)and “Ballad of a Trader's Wife"(长干行). The first poem is quite special, because the words that contain the color word “青” cover all the connotations of “青”, which is relatively rare in all the poems of Li Bai. Among these words, the English translation of the word “青云梯” involves obvious errors, so it is regarded as one of the misunderstood words to be discussed. Secondly, there is something wrong with the English translation of the word “青丝” that appears in “Qiang Jin Jiu”. In addition, when the poem "Ballad of a Trader's Wife" is translated, the English translation of the word “青梅” is not very accurate. Li Bai's three poems are relatively classic at home and abroad (Wang Feng, 2011). As the cultural exchange between China and the rest of the world is getting closer, misunderstanding is an obstacle that needs attention.

\subsection{Translations of “青云梯”, “青丝” and “青梅”}

According to the three basic meanings of “青”, the following terms “青云梯”, “青丝” and “青梅” respectively reflect the different usage of “青". Let us look at their respective English translations in context.

\subsubsection{When “青” Refers to Blue}

(1) 脚着谢公屐, 身登青云梯。

Table1: The word “青云梯” and its translations

\begin{tabular}{|c|c|c|c|c|}
\hline Original & $\begin{array}{c}\mathrm{Xu} \\
\text { Yuanchong }\end{array}$ & $\begin{array}{c}\text { W. J. B. } \\
\text { Fletcher }\end{array}$ & Yang Xianyi & $\begin{array}{c}\text { Witter Bynner\& } \\
\text { Kiang Kang-hu }\end{array}$ \\
\hline 青云梯 & $\begin{array}{c}\text { the } \\
\text { mountain } \\
\text { ladder to the } \\
\text { blue cloud }\end{array}$ & $\begin{array}{c}\text { the dun } \\
\text { clouds } \\
\text { ladder }\end{array}$ & $\begin{array}{c}\text { the dark } \\
\text { ladder of } \\
\text { clouds }\end{array}$ & $\begin{array}{c}\text { a ladder of blue } \\
\text { cloud }\end{array}$ \\
& & & \\
\hline
\end{tabular}

$\mathrm{Xu}$ :

I put Xie's pegged boot

Each on one foot,

And scale the mountain ladder to the blue cloud.

Fletcher: $\quad$ Bound on my feet the clogs were used by Hsieh of old,

Mounting the dun clouds ladder,

Yang: $\quad$ Donning the shoes of Xie,

I climbed the dark ladder of clouds.

Bynner \& Kiang: $\quad$ I wear his pegged boots

Up a ladder of the blue cloud, 
According to the context of the original verse, it can be judged: “青云梯” here refers to the mountain ladder leading to “青云”, and “青云" is a simplified saying of " white clouds in the blue sky". Because that is familiar to the source language readers, there are no annotations in the original. Having known the exact context, Xu grasps the original author's informative intention and uses the literal translation method. However, at the same time, he neglects the target language readers' cognitive ability, because the target language readers can hardly relate to the original message, that is, "white clouds in the blue sky", only according to the translation "blue cloud". Instead, they will wonder why the cloud is blue? Therefore, the translation "blue cloud" does not achieve the optimal relevance of the original. Fletcher's translation indicates that he does not understand the original author's informative intention in the context: the ladder in the original is not the clouds ladder, but a mountain ladder leading to the blue sky. In the translation of the color word "青”, Fletcher takes into account the target language readers' expectancy, so the word "dun" is used here to show the color of clouds, but meanwhile, it distorts the true meaning of “青". Yang's translation also regards the mountain ladder in the original poem as clouds ladder, in order to conform to the reading expectation of the target readers, "青” is misunderstood as "dark". In the translation of Bynner\& Kiang, part of the original author's informative intention is misinterpreted. “青云梯” is literally translated into "a ladder of blue cloud", and the optimal relevance of the original is not passed to the target language readers. In view of the above analyses, the authors believe that when we translate the word “青云梯”, we might as well use the strategy of alienation and add annotations: a ladder to blue-cloud, blue-cloud=white clouds in the blue sky.

\subsubsection{When “青” Refers to Black}

(2) 君不见, 高堂明镜悲白发, 朝如青丝暮成雪。

Table 2: The word "青丝" and its translations

\begin{tabular}{|c|c|l|c|c|}
\hline Original & Xu Yuanchong & $\begin{array}{l}\text { W. J. B. } \\
\text { Fletcher }\end{array}$ & Arthur Waley & $\begin{array}{l}\text { Witter Bynner\& } \\
\text { Kiang Kang-hu }\end{array}$ \\
\hline 青丝 & silk-black & glossy black & threads of silk & silken-black \\
\hline
\end{tabular}

$\mathrm{Xu}$ :

Do you not see the mirrors bright in chambers high grieve o'er your snow-white hair though once it was silk-black?

Fletcher: $\quad$ How thy hair to grey is growing, sadly in yon mirror Spy-

Snow at eve that but this morning showed so glossy black!

Waley: See at the mirror in the High Hall

Aged men bewailing white locks -

In the morning, threads of silk,

In the evening flakes of snow.

Bynner\& Kiang: See how lovely locks in bright mirrors in high chambers, though silken-black at morning, have changed by night to snow. 
According to the context of the original verse, it can be judged that “青丝” here does not refer to "blue thread" as literally meant, but "black hair". In traditional Chinese culture, the color word “青” not only indicates the life color of the plant itself but also symbolizes the status of "youth". When people are in youth, their hair is always black. In combination with the context, Xu determines that “青丝” refers to black hair, and then according to the reading expectations of the target language readers, the translation creates the greatest contextual effect. Fletcher also grasps the original author's informative intention and smoothly passes the message "black hair" to the target language readers. Waley hasn't found the optimal relevance of the original. He only grasps that the hair is like silk thread, but ignores the more important information that the hair is black. Thus, the translation "threads of silk" fails to create the greatest contextual effect, and the target language readers will be confused: why threads of silk are mentioned here? Having determined the original informative intention according to the context, Bynner has focused on the color word “青". His use of "silken-black" is faithful to the source information, and it satisfies the expectations of the target readers by achieving the greatest contextual effect. In view of the above analyses, the authors think that when we translate the word "青丝" in the poem, the attention should be placed on the color word “青”, and the material word “丝” is less important.

\subsubsection{When “青” Refers to Green}

（3）郎骑竹马来, 绕床弄青梅。

Table3: The word “青梅” and its translations

\begin{tabular}{|c|l|l|l|l|}
\hline Original & Ezra Pound & $\begin{array}{l}\text { W. J. B. } \\
\text { Fletcher }\end{array}$ & $\begin{array}{l}\text { Shigeyoshi } \\
\text { Obata }\end{array}$ & $\begin{array}{c}\text { Xu } \\
\text { Yuanchong }\end{array}$ \\
\hline 青梅 & blue plums & $\begin{array}{l}\text { green-gage } \\
\text { branches }\end{array}$ & $\begin{array}{l}\text { green } \\
\text { plums }\end{array}$ & $\begin{array}{l}\text { mumes still } \\
\text { green }\end{array}$ \\
\hline
\end{tabular}

Pound: You came by on bamboo stilts, playing horse,

You walked about my seat, playing with blue plums.

Fletcher: You riding came on hobby-horse astride,

And wreathed my bed with green-gage branches o'er.

Obata: You would come, riding on your bamboo horse,

And loiter about the bench with green plums for toys.

$\mathrm{Xu}$ : On hobby horse, he came upon the scene;

Around the well, we played with mumes still green.

In the original poem, "青梅" refers to the green plum, which can be used as a toy to play with, because of its spherical shape. Ezra Pound might not be very clear about its actual color, because of the geographical difference. Thus he translates "青" into "blue" literally. In fact, the original informative intention is distorted, and the target language readers will be puzzled: there are blue plums? Fletcher's cultural knowledge almost meets the requirements for the intended reader and he can accurately understand the meaning of "青梅". In addition, it is 
necessary to point out that every translator might have different understandings of the word "床" in the original poem. Thus, Fletcher likewise slightly changes the translation of "青梅" in this verse, but its image presented is not damaged. Both Obata's and Xu's translations have succeeded in creating the greatest contextual effects, so the target readers can quickly associate "青梅” with the round green plums. In view of the above analyses, the authors believe that when translating “青梅”, it is more appropriate to translate “青” into “green”.

\section{CONCLUSION}

As the essence of Chinese classical literature and culture, Tang poetry not only writes a glorious chapter on Chinese history but also enriches the diversity of world literature. It is worth noting that the use of color words in Tang poetry is not random, but conveys the obscurity aesthetics of poetry in a concise and vivid way. Among the basic color words, the color word "青" frequently appears in Tang poetry, conveying the beauty of the poems. However, its ambiguity also poses challenges for translating. Based on the misunderstanding of the words containing "青" in the three poems of Li Bai's classics, this study makes a comparative analysis of the relevant translations from the perspective of Relevance Theory. It reveals that all translations that accurately translate the color word “青” have achieved the greatest contextual effect and optimal relevance.

\section{Acknowledgement}

This work was supported by the National Social Science Fund of China under Grant [Key Project 17AZD040]; Hubei

Provincial Institutions of Higher Education Humanities and Social Sciences Research Award under Grant [2018ZA31]

\section{References}

[1] Bynner, Witter and Kiang Kang-hu. The Jade Mountain: A Chinese Anthology, Being Three Hundred Poems of the T'ang Dynasty, 618-906. New York: Knopf, 1929.

[2] Chen, Lili. Analysis of the Social and Cultural Differences between Chinese and English Color Words. Journal of PLA University of Foreign Languages, 1996 (02): 40-44.

[3] Fletcher, W.J.B. Gems of Chinese Verse. Shanghai: The Commercial Press, 1919.

[4] Ji, Lanfen. Culture Defaults and the Strategies of Culture Compensation in Color Words Translation. Journal of Qinghai University for Nationalities, 2009, 35 (03): 142-144.

[5] Li, Taizhi. The "Non-correspondence" of the Corresponding Words and the "Color Change" of Mutual Translation. Rhetoric Study, 2004 (06): 71-72.

[6] Liang, Manli. Refraction of Color Words in Chinese and English Languages. Foreign Languages Research, 2004 (04): 44-46.

[7] Liu, Suping. Analysis of Different English Translations of “青” in Tang Poetry. Science \& Technology Information, 2010 (18): 145.

[8] Obata, Shigeyoshi. The Works of Li Po.New York: E.P. Dutton \& Co., 1922.

[9] Peng, Qiurong. The Cultural Connotation of English and Chinese Color Words and Their Translation. Chinese Science \& Technology Translators Journal, 2001 (01): 30-33.

[10] Sperber, D. \& Wilson, D. Relevance: Communication and Cognition. Oxford: Blackwell, 1986.

[11] Wang, Feng, Ma Yan. A Critical Anthology of Tang Poetry and their English Translations. Xi'an: Shanxi People's Publishing House, 2011.

[12] Xu, Shen. Shuo Wen Jie Zi. Beijing: Zhonghua Book Company, 1963.

[13] Xu, Zhaohua. Analysis of the Connotation and Evolution of “青” as a Color Word. Journal of Nankai University, 1988 (6): 33-39.

[14] Yao, Xiaoping. On the Evolution of Chinese Basic Color Words. Foreign Language Teaching and Research, 1988 (01): 
IRA-International Journal of Education E Multidisciplinary Studies

19-28+80.

[15] Ying, Li, Ye Qiusheng. On the Color Word “青” in Tang Poetry. Journal of Ningde Normal University, 2007 (01): 83-86.

[16] Zhao, Jing. Comparison and Translation of English and Chinese Color Words. Journal of PLA University of Foreign Languages, 1999 (S1): 92-93+110.

[17] Zhang, Xiaonan. A Comparative Analysis of the Associative Meanings of Chinese and English Color Words. Journal of Shaanxi Normal University, 2002 (S2): 196-201.

[18] Zhou, Yingli, Xu Huiyan. On the Transmission of Optimal Relevance of Entailment in Tao Yuanmin's Poetry in English Translation. Foreign Languages Research, 2018, 35 (05): 74-79. 